\title{
Replicating European smart cities?
}

\section{The replication rationale in European Union mission statements and in practice}

\author{
Claudia Mendes, Munich Center for Technology in Society, Technical University of Munich, Augustenstr.46,80333 München (claudia.mendes@tum.de)
}

(D) https://orcid.org/0000-0002-8127-7786

The paper unpacks the notion of "replication" within the European Innovation Partnership on Smart Cities and Communities from two perspectives: The first focuses on the rationale of replication as laid out in the mission statement and integral to its vision of a European smart city market and interrogates the term borrowed from laboratory science. The second turns to replication in practice and explores how replication work, rather than providing standardized technological solutions, has harmonized the vocabulary of replication narratives, creating repositories of modularized descriptions of solutions for knowledge exchange and inspiration. The conclusion draws attention to how the focus on describing technical details precludes a more fundamental or even public debate on measures, and how the apparent failure to create a mass market for smart city technologies results in an increased access to "soft policy options," making the European smart city an increasingly governable entity.

\section{Replikation europäischer Smart Cities?}

Die Replikationslogik in EU-Leitlinien und in der Praxis

Der Beitrag beleuchtet den Begriff der "Replikation“ innerhalb der Europäischen Innovationspartnerschaft für Intelligente Städte und Gemeinden aus zwei Perspektiven: Im ersten Fall liegt der Fokus auf der Logik der Replikation, wie sie im Leitbild dargelegt und Bestandteil der Vision eines europäischen Smart-City-Marktes ist, und es wird der aus der Laborwissenschaft entlehnte Begriff hinterfragt. Im zweiten Fall wird die Replikation in der Praxis betrachtet und untersucht, wie die Replikationsarbeit, anstatt standardisierte technologische Lösungen bereitzustellen, das Vokabular von Replikationsnarrativen harmonisiert und Archive mit modularisierten Lösungsbeschreibungen für den Wissensaustausch und zur Inspiration geschaffen hat. Abschließend wird betont, dass die Konzentration auf die Beschreibung technischer Details eine grundlegendere oder gar öffentliche Debatte über Maßnahmen verhindert, und dass das offensichtliche Scheitern, einen Massenmarkt für Smart-City-Technologien zu schaffen, zu einem verstärkten Zugang

This is an article distributed under the terms of the Creative Commons Attribution License CCBY 4.0 (https://creativecommons.org/licenses/by/4.0/)

https://doi.org/10.14512/tatup.30.1.17

Submitted: 18. 09.2020. Peer reviewed. Accepted: 01.02.2021 zu „weichen politischen Optionen" führt, die die europäische Smart City zu einer zunehmend regierbaren Einheit machen.

Keywords: European Union (EU), innovation policy, replication, smart cities, urban planning

\section{Introduction}

In 2012, the European Commission initiated the European Innovation Partnership on Smart Cities and Communities (EIP SCC). Bringing together participants from tech industry, transport and energy as well as research institutions with representatives of local authorities, the partnership's goal was to formulate a mission statement for a European smart city strategy, issued in 2013 as the Strategic Implementation Plan (EIP SCC 2013) and translated into a Horizon 2020 work program by 2014/15 (European Commission 2015). Since then 17 so-called 'lighthouse projects' have been funded as innovation actions in cities across Europe. Lighthouse consortia consist of two to three lighthouse cities and two to three follower cities. They are public-private partnerships led by municipal administrations and include big tech corporations, small and medium-sized enterprises, non-governmental organisations and research institutions. These lighthouse consortia are supposed to test new technologies across the sectors of energy, transport and ICT in order to save $\mathrm{CO}_{2}$ emissions and demonstrate how smart and sustainable urbanism should look like in and how it can spread across Europe. As such, the EIP SCC is not only intervening in urban development in specific localities, but also actively shaping the making of Europe as a territorial, political and economic project.

The term replication - as part of a broader scientific terminology - has been an integral element of the European smart city discourse early on. It found its way into the lighthouse projects' architecture through the integration of follower cities and dedicated work packages, has given rise to innumerable reports, toolkits and guidelines issued in the name of replication, and meanwhile assembles a regular trans-consortial task force. In this pa- 
per, I unpack the notion of 'replication' by tracing the inherent meanings and conceptualizations. As many different actors and institutions have been involved in drafting the mission statements this is not about these actors' individual usages, but rather about what the rhetoric of the replication rationale achieves in practice: it helps producing an imaginary (however unrealistically for practical or political reasons), in which local specificity is overcome, or at least sufficiently reduced, to allow concrete technological solutions to be replicated in different cities across Europe and thus create a market for smart city technologies.

The centrality of the notion of replication and the practices entailed by it within the EIP SCC raise important questions: What

\section{It is relevant \\ to unpack the notion of 'replication'.}

does the appropriation of the concept of 'replication' in the Strategic Implementation Plan tell us about the way cities and Europe are (re-)conceptualized? To what ends and to whom is replication work of value, and who/what gets excluded? And how can the analysis of replication efforts help us understand the processes of urban development and European governance at stake?

The paper explores these questions from two perspectives: The first focuses on the EIP SCC's rationale of replication as laid out in the mission statement and integral to its vision of a European smart city market. It interrogates the definitions and theorizations that come with the term borrowed from laboratory science, and identifies a number of problems raised by both the explicit rationale and the inherent meanings of 'replication' for cities and the European project. The second part turns to replication in practice in the lighthouse consortia and explores how instead of achieving standardized technological solutions communication about replication has standardized the vocabulary of replication narratives, thus leading to the creation of repositories with modularized descriptions of solutions. The conclusion draws attention to how the focus on descriptions and definitions of technical details precludes a more fundamental or even public debate of measures, and that the apparent failure to produce traveling technologies and a mass market for smart city technologies results in an increased access to 'soft policy options' (Shore 2011), which turn the European smart city into an increasingly knowable and governable entity.

I draw on Science and Technology Studies (STS) and STS-inspired work from related disciplines. My empirical material consists of strategic policy documents, project deliverables from lighthouse consortia, stakeholder interviews as well as field notes from collaborative ethnography as partner in one of the lighthouse projects, the Smarter Together (ST) consortium, between 2016 and 2020.

\section{The laboratory rationale of replication}

In the European Commission's Communication that launched the EIP SCC in 2012, replication was already part of the terminology describing the task ahead: The EIP SCC would "pay attention" to "the potential for scale-up and replication" (European Commission 2012, p. 5), it is "tailor made" to "allow replication in cities across Europe" (p.11), and expects the commitment "to support [...] replication [...] in other cities" (p. 13).

As a term that conventionally belongs to laboratory science, 'replication' comes with some baggage relevant to consider. The use of experimental vocabulary to name or account for processes associated with urban development is part of a larger trend. Empirically, a growing number of 'living labs' and 'urban experiments' take shape in cities across the globe, which in return have triggered scholarly engagement and scrutiny at the intersection of STS, Urban Studies and Transition Studies. This literature on urban laboratories has generally focused on the situatedness and boundedness of urban experiments and their potential to reconfigure urban governance processes and futures (Karvonen and van Heur 2014; Tironi and Criado 2015), and to engender change towards a more sustainable organization of urban life (Bulkeley et al. 2014; Evans et al. 2018a). The aspect of replication, however, has so far received little attention and mostly been criticized as a remnant of positivist science, lacking to acknowledge the complexity of urban realities (Evans et al. 2018 b; Hajer 2018).

Since replication fulfils a particular function within the experimental process of laboratory science and occurs generally only after the original experiment itself, it is relevant to unpack this notion briefly. First, within the realm of laboratory experiments set out to establish new phenomena, replication serves the purpose of scientific validation: valid scientific claims need to be reproducible, that is, if an experimental procedure is followed closely in another laboratory, it must yield 'the same' results. Standardization of procedures, thorough documentation and protocols as well as equivalence between the experimental settings, are thus core elements of replicability in science, achieved through laborious and costly processes (Mallard 1998; O'Connell 1993). Furthermore, extensive studies of replication within the Sociology of Scientific Knowledge (SSK) have identified a paradox called the 'experimenter's regress' (Collins 1985): Within 'routine' science success or failure of replication allows for a judgement of competence of practitioners. When it comes to replication of 'frontier science' experiments, however, failure of replication is ambiguous: either there is no new phenomenon to be found or the experimenter is incompetent. The judgement of similarity or difference of the results and thus the success or failure of replication, is the result of scientists' interpretative work, and do not inhere in the experiments at stake (Collins 1985, 2010; Mulkay 1988). Collins' work thus adds another issue to the concept, that of interpretative flexibility when it comes to judging the success or failure of replication. 


\section{Replication for European smart cities}

I will now turn to the EIP SCC and unpack the main rationale behind the notion of replication as laid out in the EIP SCC's consecutive mission statements (EIP SCC 2013; European Commission 2012, 2015). The EC's 2012 Communication refers to replication in rather general terms as "learning from tested 'template' solutions that [...] allow replication in cities across Europe” (European Commission 2012, p. 11). In order to allow replication to happen the document establishes two prerequisites: thorough documentation and knowledge sharing - it is paramount "to measure, collect and disclose data in common formats that are necessary for further replication" (p. 13) -, and the necessity of standardization:

"Standardisation can [...] support industrialisation of solutions; align approaches between city systems; speed replicability, and help to create scale. [...] Developing [...] smart city standards is necessary, important, and non-trivial." (EIP SCC 2013, p. 15)

So far, template solutions, knowledge sharing and standardization suggest a similar logic of replication to that of laboratory science: Cities - like scientific laboratories - can and should be made equivalent (i. e. standardized), so that they can carry out similar procedures and implement similar technologies yielding similar results. The problem hindering such standardization in the case of smart cities, however, is identified in local specificity: tion Plan clearly states the vision to "create a European market" (EIP SCC 2013, p. 20), a vision which is supposedly achieved through replication of smart city technologies:

"By sharing solutions, more cities can apply similar approaches, and benefit from common designs and innovations. This will create scale, thus lowering costs and create a stronger business that can more readily attract investors. [...] Successful lighthouse initiatives will provide a solid foundation and give confidence to other cities, in the knowledge they can apply tested solutions [...] that will be better, faster, and cheaper to implement” (p. 21).

Rather than the purpose of validating results achieved in one city by another, replication within the EIP SCC then serves the purpose of establishing a critical mass of potential customers for an emerging smart city market. According to the mission statement's rationale, the standardization of cities' infrastructures and procedures modelled after the solutions implemented and demonstrated as successful in lighthouse cities will allow smart technologies to travel to other cities across Europe. Follower cities as replicators implement the same products and services, so that mass production makes them profitable for companies to produce and cheaper for cities to buy. Urban development here emerges as a purely technical matter of applying technological solutions to known problems, and whose diagnosis and treatment are equally applicable to different and distant cities.

\section{Replication serves the purpose of establishing a critical mass of potential customers for an emerging smart city market.}

"The challenge of deploying solutions related to the energy, transport and ICT sectors [...] in an urban environment is to overcome the local specificities. Consequently actions and actors which can ensure the transferability of solutions and create the framework for replicability of solutions should be prioritised and rewarded." (European Commission 2015, p. 82)

Or, as one of my interlocutors from the involved Directorate Generals put it in more concrete terms, referring to material requirements for public transport vehicles:

"Many cities think that they are in a unique situation, and that holds back a lot of the market opportunities. [...] We know that big industry players could provide those solutions much cheaper, if some of the cities would just get over the $5 \mathrm{~mm}$ higher or $5 \mathrm{~cm}$ lower entry door issue." (policy officer, May 14, 2018)

What becomes clear in this quote, is how in the EIP SCC's rationale, replication via standardization is linked to another dimension, namely that of the market. The Strategic Implementa-
This replication rationale is finally anchored in the future lighthouse projects' architecture - "Initiatives must integrate (...) replicability from the outset, with allocation of resources for that purpose" (EIP SCC 2013, p. 15) -, and results in a consortial set up of three lighthouse cities and three follower cities, who commit to replicating measures implemented by the lighthouse cities during the project.

\section{Uneven geographies of replication and standardisation}

The logic of replication as enacted in the EIP SCC raises serious concerns regarding the political economy of who gets to experiment, assess potential risks of and set standards for such technologies; and who is supposed to adopt (and therefore adapt) to the lighthouse cities' model. This concern becomes more pronounced when we look at the specific geography entailed by the EIP SCC: as part of Horizon2020 framework program (FP), the main instrument of EU innovation policy, funding is allocated on a competitive basis. As such, the EIP SCC program is 
prone to what the 2018 study of the European Parliamentary Research Service called "uneven participation": "participation appears to be biased against an entire region of the EU. After almost 20 years of access to the opportunities of the FPs, the EU-13 countries are still lagging behind the EU-15" (Pazour et al. 2018, p. 1). Unsurprisingly, the spatial distribution of beneficiaries shows a clear East-West divide between lighthouse cities on the one hand, and follower cities on the other. The underlying funding scheme of the first generation of lighthouse projects makes the apparent inequalities for participation between the lighthouse cities as models and the follower cities as replicators even more pronounced: While the former receive funding for the implementation of smart city technologies, the latter can only claim resources for travel and peer-to-peer exchange. Thus, as one of the representatives of a ST follower city put it, "it feels like being invited to the table to watch the others eat" (local public official, October 30, 2018).

Besides this structural problem of uneven participation and its consequences, the rationale of replication within the EIP SCC's mission statement also raises more practical issues. As the previous analysis has shown, the replication of smart cities is imagined to work along the lines of standardization which allows for a smooth technology transfer and the emergence of a smart city market. According to this vision, a smart lamppost, once successfully implemented by lighthouse cities, can travel as a fairly fixed and stable entity to distant places. Yet, the smart lamppost developed and tested in the ST project, has been tailored to the aesthetic, regulatory and practical requirements of the lighthouse city Munich: it needs to look from the outside exactly as all the other lampposts in the city, it needs to have two independent circuits so that lighting can be maintained as usual without potential interference of flawed sensor infrastructures, and the size of openings, type of plug-ins and APIs for interoperability between lamppost, sensor and data platform have been discussed and pre-defined in collaboration with potential local sensor providers. As authors like Akrich (1993; 2006) have demonstrated in numerous case studies, already very minor elements can lead to the collapse of such a network of materials, procedures, skills and social relations, no matter how carefully designed and tested in one place. At best, transfer of technologies always involves situated and laborious processes of translation and thus a more fluid and less stable conceptualization of technological objects themselves. Comparable difficulties have been described for the travel of policies (McCann and Ward 2013, 2014), of concepts and practices between urban administrations (Czarniawska-Joerges 2002) as well as innovation models (Pfotenhauer and Jasanoff 2017).

\section{Replication in practice}

While the easy account to give here, would be to tell a story of failure of either of such replication attempts due to local specificity and complexity, the earlier discussion of SSK literature on replication has shown that the judgement of success or failure is itself subject to interpretative flexibility, even within the realm of hard science. It is therefore of little use to tell such a story. Rather, I want to turn to the practical effects of the replication rationale in terms of how it gives rise to a narrative of replication, of how it leads, quite opposite to the initial aim, to modularized solutions and of how it incites knowledge exchange.

\section{Communication about replication, modularization instead of standardization}

The mandate to foster 'replication', however vaguely defined, has triggered huge efforts within the EIP SCC's lighthouse projects: dedicated work packages have been established; follower cities have been recruited; workshops, webinars and peer-2-peer meetings have taken place and countless reports, guidelines, toolkits, strategies and policy papers have been produced on the topic by each of the consortia. The ST consortium alone has issued (see appendix): a 'Replication Framework' (appendix 1), a 'Smart City Toolbox - Replication Toolkit' (appendix 2), a 'Preparing for Replication' deliverable for each of the three lighthouse cities including 'Solution Blueprints' and 'Short Guides', and a 'Replication Strategy' for each of the three follower cities (appendix 3; appendix 4; appendix 5).

In order to coordinate cross-consortial collaboration on the topic and to orchestrate the sheer amount of replication documents and approaches produced by all consortia, the EIP SCC has set up a task group on replication. The participants engage in monthly online meetings where they present each other's approaches and formulate an annual action plan. One of the key targets of that action plan is to

"gather in the common repository (OneDrive) all Lighthouse project's Deliverables on and tools for replication, especially from the first Lighthouse projects. Examples: replication roadmaps, tool catalogues, toolkits, replication potential assessment tools". (appendix 6)

Being the result of joint intra- and trans-consortial efforts to make replication happen, these documents mostly draw on the practical experiences of urban planners involved in implementing specific smart solutions, and aggregate those experiences into commonly developed categories. An attempt to standardize the evaluation of what counts as a smart city best practice by the ST project resulted in a DIN workshop agreement on the description of good practices - which aspects need to be mentioned, in which detail and how to structure them. Instead of standardizing technologies or cities for a market to emerge, what seems to be harmonized here, are the tools for narrating different urban planning experiences. These collaborative processes thus help establishing a common vocabulary across cities, and simultaneously render those descriptions more comparable and assessable. The ST 'Replication Framework', for instance, designed to help future replicators to assess the replication-potential of a specific solution, defines three areas where similarity is a variable determining the 'probability of success': type 
and quality of data, built environment and governance structures (Smarter Together 2019).

\section{Replication as knowledge exchange}

It is crucial however, that replication here is not assumed to imply other cities adapting their available data, built environment or legal framework to become more similar. Rather, the solutions described in the replication framework contribute to a growing repository, which at some point might cover sufficiently different contexts and modularized solutions as to allow any other city to identify commonalities and differences with lighthouse cities and then handpick and tailor procedures and artifacts to their needs and local specificities. The joint policy paper by three other lighthouse consortia makes this aspect more explicit:

"Smart solutions can be replicated by adapting the original idea to a new context [...]. There are two important aspects [...]: i) determine transferrable units, and ii) find the window of opportunity. Transferrable units refers to viewing the project as the sum of its parts and determining which of those parts are able to be transferred directly, and which need to be adapted. These parts could then be repackaged as a new solution customized to the new location, with a higher chance of success." (Garcia-Fuentes et al. 2019, p.9)

While representatives of follower cities directly involved in replication work praise the value of such "inspiration" and the opportunity "to see what could be done" (informal conversations, 2020), an interlocutor from DG CONNECT expresses his dis- post, but stories and descriptions. Replication becomes a process of knowledge exchange, mutual learning and inspiration. Repositories decouple replication from standardization and allow for a multiplication of technologies and approaches through ever new modular re-combinations and adaptations to local contexts.

\section{Conclusion}

These findings seem to indicate that from a European Commission's perspective, the replication rationale as laid out in the mission statement has failed as a market device. However, I argue, the work and the output of the activities carried out in the name of replication within the EIP SCC do something else for the making of Europe and urban development respectively. First, the sheer amount of work put into making replication happen focuses resources on the discussion of technical details and the minute description of implementation procedures of the respective measures. It thereby takes them away from engaging in a more general and possibly public debate of whether ICT solutions are at all suited to tackle urban problems like climate change, let alone from opening up the problem definition in the first place.

Second, according to the principles of conferral and subsidiarity (European Union 2012), cities and urban development do not fall under the competence of European institutions. Yet, replication work resulting in best practice storytelling, self-docu-

\section{Replication work opens up urban development as new area for European governance and reinforces urban politics as 'technical' matters.}

appointment with the resulting diversity. The urban data platforms tested in the consortia did not funnel down to a few favorite standard solutions, but instead each city choses different providers and architectures:

"The challenge is that very often within the project, the three different lead cities [...], they had three different ICT solutions. So how do you replicate, if even within one project you have three different types of solutions? And across the portfolio of all the Lighthouse projects, it's even more diverse." (Policy Officer, May 14, 2018)

What those insights show, is that rather than standardizing specific solutions (to be produced at scale for the smart city market), the observable effects of replication work are an ongoing dialogue and exchange between cities across Europe on best practices, challenges and self-evaluation, and the production of an ever-growing online repository. What travels then are not so much technological artefacts, such as the Munich lamp- mentation and evaluation - tasked and regularly reviewed by European agencies -, corresponds to what Shore has called 'soft-policy options':

"the emphasis is not on direct regulation or intervention from above, but rather on indirect methods of benchmarking, peer review, self-evaluation and so on. The effect of these socalled 'soft-policy' options [...] is to make Europe and its population 'visible' to the calculative practices of EU officials and administrators.” (Shore 2011, pp. 298-299)

The repository as a growing body of knowledge and expertise turns cities into more visible, measurable and knowable entities, and indirectly renders them more governable. Replication work, taking place under the supervision of the European Commission, thus opens up urban development as new area for European governance and reinforces urban politics as 'technical' matters to be discussed and decided between administrative and technical experts rather than through public debate. 


\section{Funding declaration}

The author has received funding from the European Union's Horizon 2020 research and innovation programme under grant agreement No. 689527.

\section{Appendix}

Documents issued by the Smarter Together consortium.

(All URLs last accessed on 28. 01.2021.)

(\#1) Replication framework. Deliverable D8.1.1, available online at https://www.smarter-together.eu/fr/file-download/download/public/1177.

(\#2) Smart city toolbox. Replication toolkit, available online at https://www.smarter-together.eu/file-download/download/public/1621.

(\#3) Integrated urban replication strategy of Sofia municipality, available online at https://www.smarter-together.eu/file-download/download/ public/1887.

(\#4) City of Venice. Integrated urban replication strategy, available online at https://www.smarter-together.eu/file-download/download/public/1269.

(\#5) Integrated urban replication strategy Santiago de Compostela, available online at https://www.smarter-together.eu/file-download/download/ public/1027.

Action plan issued by the EIP SCC task group on replication

(\#6) Task group replication action plan 2020-21 v.05, available online at https://onedrive.live.com/view.aspx?cid=6b299de69b919596\&page=view\&res id=6B299DE69B919596!3558\& parld=6B299DE69B919596!1962\&authkey=!AqQ8miACHHnoAA\&app $=$ Word.

\section{References}

Akrich, Madeleine (1993): Essay of technosociology. A gasogene in Costa Rica. In: Pierre Lemonnier (ed.): Technological choices. Transformation in material cultures since the Neolithic. London: Routledge, pp. 289-337.

Akrich, Madeleine (2006): La construction d'un système socio-technique. Esquisse pour une anthropologie des techniques. In: Madeleine Akrich, Michel Callon and Bruno Latour (eds.): Sociologie de la traduction. Paris: Presses des Mines, pp. 109-134. https://doi.org/10.4000/books.pressesmines.1195

Bulkeley, Harriet; Castán Broto, Vanesa; Maassen, Anne (2014): Low-carbon transitions and the reconfiguration of urban infrastructure. In: Urban Studies 51 (7), pp. 1471-1486. https://doi.org/10.1177/0042098013500089

Collins, Harry (1985): Changing order. Replication and induction in scientific practice. London: Sage Publications.

Collins, Harry (2010): Gravity's shadow. The search for gravitational waves. Chicago: University of Chicago Press.

Czarniawska-Joerges, Barbara (2002): A tale of three cities. Or the glocalization of city management. Oxford: Oxford University Press.

EIP SCC - European Innovation Partnership on Smart Cities and Communities (2013): Strategic implementation plan. Brussels: European Innovation Partnership on Smart Cities and Communities.

European Commission (2012): Smart cities and communities. European innovation partnership. Communication from the Commission. Brussels: European Commission. Available online at https://ec.europa.eu/newsroom/dae/ document.cfm?doc_id=3178, last accessed on 29.01.2021.

European Commission (2015): Horizon 2020. Work programme 2014-2015. Secure, clean and efficient energy. Brussels: European Commission.

European Union (2012): Consolidated version of the treaty on the functioning of the European union. Available online at https://eur-lex.europa.eu/ resource.html?uri=cellar:2bf140bf-a3f8-4ab2-b506-fd71826e6da6.0023.02/ DOC_1\&format=PDF, last accessed on 05.01.2021.

Evans, James; Karvonen, Andrew; Raven, Rob (2018 a): The experimental city. New modes and prospects of urban transformation. In: James Evans, Andrew Karvonen and Rob Raven (eds.): The experimental city. London: Routledge, pp. 1-12. https://doi.org/10.4324/9781315719825-1

Evans, James; Karvonen, Andrew; Raven, Rob (eds.) (2018 b): The experimental city. London: Routledge.

Garcia-Fuentes, Miguel et al. (2019): From dream to reality. Sharing experiences from leading European smart cities. Valladolid: Grow Smarter.

Hajer, Maarten (2018): Foreword. In: James Evans, Andrew Karvonen and Rob Raven (eds.): The experimental city. London: Routledge, pp. xvii-xix.

Karvonen, Andrew; van Heur, Bas (2014): Urban laboratories. Experiments in reworking cities. Introduction. In: International Journal of Urban and Regional Research 38 (2), pp. 379-392. https://doi.org/10.1111/1468-2427.12075

Mallard, Alexandre (1998): Compare, standardize and settle agreement. On some usual metrological problems. In: Social Studies of Science 28 (4), pp. 571-601. https://doi.org/10.1177/030631298028004003

McCann, Eugene; Ward, Kevin (2013): A multi-disciplinary approach to policy transfer research. Geographies, assemblages, mobilities and mutations. In: Policy Studies 34 (1), pp. 2-18. https://doi.org/10.1080/01442872.2012.748563

McCann, Eugene; Ward, Kevin (2014): Exploring urban policy mobilities. The case of business improvement districts. In: Sociologica 8 (1), pp. 1-20. https://doi.org/10.2383/77048

Mulkay, Michael (1988): Don Quixote's double. A self-exemplifying text. In: Steve Woolgar (ed.): Knowledge and reflexivity. New frontiers in the sociology of knowledge. London: Sage, pp. 81-100.

O'Connell, Joseph (1993): Metrology. The creation of universality by the circulation of particulars. In: Social Studies of Science 23 (1), pp. 129-173. https://doi.org/10.1177/030631293023001005

Pazour, Michal et al. (2018): Overcoming innovation gaps in the EU-13 Member States. Study. Brussels: European Parliamentary Research Service.

Pfotenhauer, Sebastian; Jasanoff, Sheila (2017): Panacea or diagnosis? Imaginaries of innovation and the 'MIT model' in three political cultures. In: Social Studies of Science 47 (6), pp. 783-810. https://doi. org/10.1177/0306312717706110

Shore, Cris (2011): 'European Governance' or governmentality? The European Commission and the future of democratic government. In: European Law Journal 17 (3), pp. 287-303. https://doi.org/10.1111/j.1468-0386.2011.00551.x

Tironi, Martin; Criado, Tomás (2015): Of sensors and sensitivities. Towards a cosmopolitics of "smart cities"? In: TECNOSCIENZA: Italian Journal of Science \& Technology Studies 6 (1), pp. 89-108.

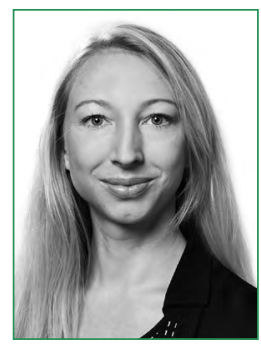

\section{CLAUDIA MENDES}

is a research associate at the Munich Center for Technology in Society (TUM) and has been an embedded researcher in the H2020 project Smarter Together. Her work is situated at the intersection of STS and Urban Studies. In her PhD project, she explores the complex interplay of European innovation policy, urban development and digitalization. 